\title{
Frameworks for mass collaboration, adaptable scripts, complex systems theory, and collaborative writing
}

\author{
Sten Ludvigsen ${ }^{1} \cdot$ Nancy Law $^{2}$ - Carolyn P. Rose ${ }^{3}$ • \\ Gerry Stahl ${ }^{4}$
}

Published online: 10 July 2017

(C) International Society of the Learning Sciences, Inc. 2017

\section{Introduction}

In computer-supported collaborative learning (CSCL) and in the learning sciences, many of the terms used to conceptualize learning activities and actions originated from the concept of communities of practice put forward by Lave and Wenger (1991). While social practices are used as key constructs in many of the social sciences, the CSCL community works with specific operationalizations of those concepts that are useful for representing and analyzing the processes through which learning occurs. Concepts like communities of learners, communities of interest, knowledge communities (Stahl 2015), and knowledge building (Chen et al. 2015) should be seen as metaphors that serve as broad stances to be further specified and used as analytical lenses. As part of this specification, the unit of analysis and level of description must also be carefully considered as part of fashioning an analytical lens for a particular study (Ludvigsen and Arnseth 2017; Suthers et al. 2013). In this issue, new contributions to stances and concepts are presented.

Sten Ludvigsen

Sten@ijCSCL.org

Nancy Law

Nancy@ijCSCL.org

Carolyn P. Rose

cprose@cs.cmu.edu

Gerry Stahl

Gerry@ijCSCL.org

1 University of Oslo, Oslo, Norway

2 University of Hong Kong, Hong Kong, China

3 Carnegie Mellon University Language Technologies Institute and HCI Institute, Gates-Hillman Center 5415, 5000 Forbes Ave, Pittsburgh, PA 15213-3891, USA

4 Drexel University, Philadelphia, PA, USA 
In this issue of the journal, we have four papers that contribute to new and emerging themes, such as mass collaboration, and offer new perspectives on asynchronous and synchronous online collaboration. We also present new work on the classical theme of scripts and scripting as well as a multi-methods study of students' collaborative writing. Across the four contributions in this issue, the authors use different research designs and methods, which we hope will engage readers in productive tensions between different approaches and yield a deeper understanding of the phenomena that are investigated in the CSCL field.

\section{Mass collaboration and CSCL}

The idea of mass collaboration has become an important theme in CSCL research, spanning both learning in online communities like Wikipedia and more formal learning platforms like Massive Open Online Courses (MOOCs) (Fischer 2016). A major focus of research in MOOCs has focused on technical innovations. Less focus has been placed on understanding and supporting the interplay between the many stakeholders, including course developers, instructors, and students who have played a role in this paradigm for online learning. On the other hand, while this might be the case for commercial MOOCs, those designed by educational researchers have paid attention to a number of features for enhancing learning (Rosé and Ferschke 2016).

In the opening article, Heisawn Jeong, Ulrike Cress, Johannes Moskaliuk, and Joachim Kimmerle argue for a new framework based on concepts and principles for the design of mass collaboration activities, such as co-editing a Wikepedia page and working in Scratch. The concepts and interaction types are attendance, coordination, cooperation, and collaboration, which they refer to as the $\mathrm{A} 3 \mathrm{C}$ framework. How participants choose to interact is dependent on their goals, tasks, artifacts, and more generally, the environment in which they perform their actions. The concepts proposed by Jeong et al. imply that social interaction can be rather loose or highly committed and intense. In a trajectory, the intensity of the group and individual participation can vary significantly over time (Alterman and Harsch 2017). However, the four types of interaction should not be viewed as a monotonic progression from simple to advanced, or seen as strongly interdependent. Jeong et al. emphasize that all four types of interactions can contribute individually to learning processes and outcomes. That these exist in parallel illustrates how complex mass collaboration is.

\section{CSCL and complex adaptive systems theory}

In many areas in the social sciences, complex adaptive systems theory has been used to explore and explain complex phenomena. However, in CSCL, except for the influential work by Ulrike Cress from the University of Tübingen, which has clearly been inspired by complex adaptive system theory (Cress and Kimmerle 2008; Cress et al. 2015), few studies have used this approach. Some of the key concepts in complex adaptive systems theory are selforganization, emergence, interdependencies, and hierarchical nesting of levels. Selforganization can be seen as rare in education because educational activities are most often heavily influenced by teacher instruction and social norms that regulate actions. In the study by Vogler et al. reported in this issue, the authors explain emerging participation in a synchronous online environment using the concept of self-organization. In order to create an analysis that 
bridges the gaps between individuals, groups, and the community, the authors have taken the group as a starting point for their analysis. In CSCL, many contributions work with transcripts that give access to understanding the sequential nature of actions. However, many synchronous interactions in online environments do not follow a typical sequence. For example, in face-toface interactions in classrooms or in work activities we may see patterns that diverge from the norm. Vogler et al. argue in this paper that self-organization can be seen as a continuum.

The data collection technique that was used (using Camtasia software) provided a unique opportunity for capturing the participants' activities on the computer, while the use of four video cameras also captured the activities that took place in the classroom. The participants in the study were graduate-students, and the data comes from one of their regular courses. The task was to discuss four articles. The environment used for the public chat space and writing space was called the "written pane." One of the many interesting findings is that there is a strong interdependence between processes and content and that there is a subtle relationship between the individual processes and the co-creation of shared experiences and meaningmaking. In the environments used by the Vogel et al., many students and teachers came up with ideas and followed up with the uptake of those ideas. One can argue that the environment encouraged and enriched the dialogues that ensued. We can hope that such openness develops a stronger agency among the students in their individual and collective efforts.

The paper by Vogel et al. provides new insight into the emerging complexity of online interactions and the way participants contribute through meaning making. We see that the use of complex adaptive systems theory can be suggestive for the CSCL community.

\section{Adaptable scripting for self-regulation}

The paper by Xinghua Wang, Ingo Kollar, and Karsten Stegman takes the research regarding scripts and scripting to a new level. Scripts and scripting are classical themes in CSCL (e.g., Dillenbourg and Jermann 2007; Fischer et al. 2013; Järvelä et al. 2016; Tchounikine 2016). This work poses the basic question of how to support and scaffold students to develop domain knowledge and regulatory skills, which can be viewed as a necessary condition for advanced work with concepts and development of future dispositions for learning (Bransford and Schwartz 1999). Many studies regarding scripts take a cognitive approach like Wang et al. do here, while others emphasize the affective/motivational factors. In addition, some authors include shared regulation, which relates to the way students in social interactions choose to regulate their work jointly (Järvelä et al. 2016).

This paper by Wang et al. investigates how adaptable collaboration scripts might make student learning more effective. The students in this study were assigned to three different conditions: adaptable collaborative scripts, non-adaptable scripts, and non-scripted collaboration. The subjects were university students in educational science and neighboring fields. The total time used by the students was three hours. The study is cast as an experimental study, and the results across the three different settings are compared with regard to effectiveness.

The results show that collaboration scripts, both adaptable and non-adaptable, decreased the planning required by the students, while in the non-script condition it increased. Planning is seen as one important aspect of self-regulation. However, reflection increases both in the adaptable and non-adaptable script conditions. Only the adaptable script had positive effects on monitoring. Wang et al. conclude that overall, adaptable collaborative scripts have a positive effect on self-regulation skills. The results give the CSCL field new insights and themes to 
further explore. Given that experiments are often rather limited with regard to time, it would be very interesting to see how self-regulatory skills develop in naturalistic settings over longer periods of time.

\section{Collaborative writing in CSCL environments}

Writing is one very important part of learning. To construct shared knowledge through writing in a group can be seen as a core activity in schools and in educational systems more broadly. In the CSCL field, there have been studies that trace the process of artifact production (see Damsa 2014; Järvelä et al. 2016; Jeong and Hmelo-Silver 2016). However, few studies have combined analysis of the qualitative processes involved and quantitative analysis of the outcomes of writing activities. In this issue, Joachim Kimmerle, Johannes Moskaliuk, Dieter Brendle, and Ulrike Cress combine different methods in their study of students in a secondary school learning about media and violence using an experimental design in which students worked on two tasks of approximately $90 \mathrm{~min}$ each. Through engaging in the assigned tasks, the students were expected to develop a text based on collaborative writing and to arrive at a shared perspective. Collaborative writing was the only mode of communication for the students.

One group of students was introduced to the theme of media violence through studies based on learning theories while the other group was exposed to arousal theories about media violence. The study employed a jigsaw paradigm in which students worked in dyads, each having been exposed to a different theoretical foundation. Thus, students within each pair started with different perspectives and knowledge about media violence as a phenomenon. The students used a digital collaboration tool, Etherpad, which provided them with affordances for collaborative text editing. The task instructions pointed to a wide range of aspects relevant to the theme and requested them to summarize their knowledge while seeking to find a shared perspective.

The analysis shows that the student's writing develops through different phases and that the sharing of opinions seems to develop in the last phase of the work. The collaborative writing is non-linear and non-cumulative through the different phases. The social and cognitive demands that are part of the task emerge through interactions, and the solution comes towards the end of the process. These findings may inspire further research to investigate the ways in which interactions in one phase are nevertheless related to interactions that occurred during earlier phases.

For the CSCL community, this study offers an ensemble of analyses that together provide important insight into collaborative and individual cognitive and social processes. This study can also be viewed as contributing to recent developments in the area of CSCL scripts (Stegmann et al. 2016; Tchounikine 2016), and we look forward to new studies based on these results, which have the potential to deepen our understanding of the social and cognitive functions involved in different phases of collaborative writing.

\section{Conclusion}

While this issue was being produced, many of us took part in the CSCL 2017 conference in Philadelphia. The inspiring keynote presentations, conference sessions of various formats, and published articles in the proceedings offer both a number of classical CSCL themes and 
contributions along with new and emerging directions for the field. We hope to see expanded versions of many of these strong papers in the journal in the coming year as we continue to reflect on the direction the field is taking into the future.

\section{References}

Alterman, R., \& Harsch, K. (2017). A more reflective form of joint problem solving. International Journal of Computer-Supported Collaborative Learning, 12(1), 9-33.

Bransford, J. D., \& Schwartz, D. L. (1999). Rethinking transfer: A simple proposal with multiple implications. In A. Iran-Nejad \& P. D. Pearson (Eds.), Review of research in education (pp. 61-100). Washington, DC: American Educational Research Association.

Chen, B., Scardamalia, M., \& Bereiter, C. (2015). Advancing knowledge-building discourse through judgments of promising ideas. International Journal of Computer-Supported Collaborative Learning, 10(4), 345-366.

Cress, U., \& Kimmerle, J. (2008). A systemic and cognitive view on collaborative knowledge building with wikis. International Journal of Computer-Supported Collaborative Learning, 3(2), 105-122.

Cress, U., Stahl, G., Ludvigsen, S., \& Law, N. (2015). The core features of CSCL: Social situation, collaborative knowledge processes and their design. International Journal of Computer-Supported Collaborative Learning, 10(2), 109-116.

Damsa, C. I. (2014). The multi-layered nature of small-group learning: Productive interactions in object-oriented collaboration. International Journal of Computer-Supported Collaborative Learning, 9(3), 247-281.

Dillenbourg, P., \& Jermann, P. (2007). Designing integrative scripts. In F. Fischer, I. Kollar, H.

Fischer, G. (2016). Exploring, understanding, and designing innovative socio-technical environments for fostering and supporting mass collaboration. In U. Cress, J. Moskaliuk, \& H. Jeong (Eds.), Mass collaboration and education (pp. 43-63). Cham, SC: Springer International.

Fischer, F., Kollar, I., Stegmann, K., \& Wecker, C. (2013). Toward a script theory of guidance in computersupported collaborative learning. Educational Psychologist, 48(1), 56-66.

Järvelä, S., Kirschner, P. A., Hadwin, A., Järvenoja, H., Malmerg, J., Miller, M., \& Laru, J. (2016). Socially shared regulation of learning in CSCL: Understanding and prompting individual- and group-level shared regulatory activities. International Journal of Computer-Supported Collaborative Learning, 11(3), 263-280.

Jeong, H., \& Hmelo-Silver, C. (2016). Seven affordances of computer-supported collaborative learning: How to support collaborative learning? How can technology help? Educational Psychologist, 51(2), 247-265.

Lave, J., \& Wenger, E. (1991). Situated learning: Legitimate peripheral participation. Cambridge: Cambridge University Press.

Ludvigsen, S., \& Arnseth, H. A. (2017). Computer-supported collaborative learning. In E. Duval, M. Sharples, \& R. Sutherland (Eds.), Technology Enhanced Learning (pp. 47-58). Cham, SC: Springer International.

Rosé, C. P., \& Ferschke, O. (2016). Technology support for discussion based learning: from computer supported collaborative learning to the future of massive open online courses. International Journal of AI in Education, 25th Anniversary Edition, 26(2), 660-678.

Stahl, G. (2015). A decade of CSCL. International Journal of Computer-Supported Collaborative Learning, 10(4), 337-344.

Stegmann, K., Kollar, I., Weinberger, A., et al. (2016). Appropriation from a script theory of guidance perspective: A response to Pierre Tchounikine. International Journal of Computer-Supported Collaborative Learning, 11(3), 371-379.

Suthers, D., Lund, K., Rosé, C. P., Teplovs, C., \& Law, N. (2013). Productive Multivocality in the Analysisof Group Interactions, edited volume. Cham, SC: Springer International.

Tchounikine, P. (2016). Contribution to a theory of CSCL scripts: Taking into account the appropriation of scripts by learners. International Journal of Computer-Supported Collaborative Learning, 11(3), 349-369. 